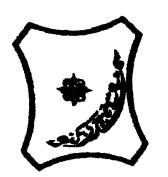

Bayero Journal of Pure and Applied Sciences, 8(1): $19-23$

Received: September, 2014

Accepted: June, 2015

ISSN $2006-6996$

\title{
SEROPREVALENCE OF HBsAg AMONG PATIENTS WITH FEBRILE ILLNESSESS IN MURTALA MUHAMMAD SPECIALIST HOSPITAL, KANO, NIGERIA
}

\author{
$*^{1}$ Mohammed, Y., ${ }^{1}$ Sharif, A. and ${ }^{2}$ Dabo, N.T. \\ ${ }^{1}$ Department of Medical Microbiology and Parasitology, Bayero University, Kano, P.M.B 3011, Nigeria \\ ${ }^{2}$ Department of Microbiology, Bayero University, Kano, P.M.B 3011, Nigeria \\ *Correspondence author : drymohd@yahoo.com; +234-80-3616380
}

\begin{abstract}
The study was carried out between the months of July and December 2013 to determine the prevalence of hepatitis $B$ surface antigen among patients presenting with febrile illnesses attending Murtala Muhammad Specialist Hospital, Kano. Two hundred (200) blood samples were obtained from the consented patients with age ranged from 15-64 years, that were processed according to standard operating procedures (SOPS) and screened for the presence of HBsAg using a third generation enzyme linked immunosorbent assay method. A total of $22(11 \%)$ patients were positive for HBsAg. Higher rate of infection was observed among males $72.2 \%(n=16)$ than their female counterparts $27.3 \%(n=6)$. Infection rate was found to be higher in age group 25-34 years, $45.4 \%(n=10)$ than $15-24$ and $35-44$ years each with $27.3 \%(n=6)$, and none was found to be positive among 45-54 and 55-64 years age groups. Also more infection was observed among the married population $54.5 \%(n=12)$ than single $40.9 \%(n=9)$ and widow $4.5 \%(n=1)$. However, high sero-positivity is also occupationally dependent. More infections were seen among business occupational groups $50 \%(n=11)$ than students $31.8 \%(n=7)$ while $18.2 \%(n=4)$ was seen among civil servants. The major route of transmission among the study group is sexual transmission in those with multiple sexual partners and history of blood transfusions. Those with history of vaccination against hepatitis $B$ had no positive result $(n=0)$. The study revealed a considerable high infection among males, married business occupation class and students these where however not statistically significantly different $(p<0.005)$, and also pointed out potency and importance of vaccination for all vaccine preventable diseases.

Key Words: Seroprevalence, Hepatitis B, Febrile Illness, Kano
\end{abstract}

\section{INTRODUCTION}

Hepatitis B infection (HBI) is one of the major public health problems globally and is the 10th leading cause of death (WHO, 2013). Worldwide, more than two billion of the populations have evidence of past or recent HBV infection and there are more than 350 million chronic carriers of this infection (Samuel et al., 2009). Individual infected with the virus can remain as carriers and asymptomatic for life with increase risk of hepatocellular carcinoma, liver cirrhosis and death from liver failure (Okonkwo et al., 2010). Routes of transmission are blood and blood products, intravenous drug abuse, unsafe injection, usage of sharps and unprotected sexual activities. Other routes of transmission are mother to child, needle stick injury among health workers, barbers, tattooing and scarification marks (Mazie et al., 2002; Paulyn et al., 2010; Okonkwo et al., 2010). The burden pose on health of individual made it necessary to carry out routing screening before blood transfusion in health facilities and more importantly to reduce its continuous spread. Hepatitis B screening is done for every pregnant woman registered for antenatal services in various health facilities. In most parts of the world adults contracts the infection through sexual contact and perinatal transmission accounts for its continuous endemicity in most endemic areas (Centre for Diseases Control, 2008).
World health organization reported in 1998 that most infections occur in adolescents and young adults with associated risk factors such as unprotected sexual intercourse, injection drug abuse, blood transfusion and body piercing as in barbing, tattooing, scarifications etc (Alao et al., 2009; Paulyn et al., 2010). Prevalence of hepatitis B infection is high in most developing countries in sub-Saharan Africa, Southeast Asia, South America (Sharma et al., 2005) and mostly detected in blood donors, people living with HIV/AIDS (PLWHA), pregnant women, students and other occupationally related groups. Prevalence of $6.5 \%, 9.2 \%$ and $6.1 \%$ were found in Kinshasa, Democratic Republic of Congo and Ethiopia respectively (Baye and Yahannes 2007).

HBV infection occurs frequently and is highly endemic in Nigeria (Abiodun and Omoike, 1990; Fakunle et al., 1981) and, the disease has an estimated $12 \%$ of population as carriers (Okonkwo et al., 2010; Ugwuja and Ugwu, 2010). Several studies were conducted in Nigeria with associated risk factors in different population, regionally and established varied prevalence.

The aim of this study was to determine the seroprevalence of $\mathrm{HBsAg}$ among patients with febrile illnesses in Murtala Muhammad Specialist Hospital, Kano, Nigeria. 


\section{MATERIALS AND METHODS \\ Study Population}

The study was carried out among patients who presented to outpatient department of Murtala Muhammad Specialist Hospital with febrile illnesses such as malaria. Age group recruited for the study were between the age of $15-64$ years who are free, from their medical records and history, of any known disease or condition such as liver diseases, cancers, hypertension, diabetes mellitus, sickle cell disease, patient on chemotherapy and pregnancy if female. Two hundred (200) patients who consented were recruited through an interviewer administered open ended questionnaire which contains sociodemographic characteristics and risk factors associated with hepatitis B viral infection. The sample size was estimated based on the local prevalence of hepatitis B viral infection.

\section{Collection of Blood Sample}

Three (3) mls of blood was collected from each patient with sterile vacutainer needle directly into a universal sterile bottle. Samples were centrifuged at $3000 \mathrm{rpm}$ for 5 minutes and the sera obtained were used for screening of HBsAg according to standard procedures (Cheesbrough 2005). For the detection of $\mathrm{HBsAg}$, chromatographic immunoassay based Micropoint test strip made in USA was used. The tests and result interpretation were done according to laboratory standard and test kits manufacturer's specifications.

\section{Ethical Approval}

Ethical approval was obtained from the Ethics and Research Committee of Hospital Management Board, Kano.

\section{Statistical Analysis}

This was done with SPSS version 20 by calculating simple percentages, association was determined by cross tabulations and statistical significance was set at $p<0.05$.

RESULTS

A total of 200 blood samples were obtained from patients that presented with febrile illnesses within the age range of $15-64$ years. The overall prevalence rate of $\mathrm{HBV}$ infection obtained among the patients was $11 \%$ as shown in Table1.

Table 1: HbsAg Positivity in Patients with Febrile Illnesses at Murtala Muhammad Specialist Hospital, Kano

\begin{tabular}{lcc}
\hline HBV Positivity & Number of Sample & Percentage (\%) \\
Reactive & 22 & 11 \\
Non- Reactive & 178 & 89 \\
Total & $\mathbf{2 0 0}$ & $\mathbf{1 0 0}$ \\
\hline
\end{tabular}

Table 2 shows some socio-demographic characteristics of the patients with HBV infection. Male patients were seen to be more infected than the female patients with $72.7 \%$ and $27.3 \%$ respectively. Age specific prevalence rate was seen among 25-34 years age groups to be $45.5 \%$ of the positive population then followed by $27.3 \%$ each for age groups 15-24 and 35-44 years. No infection recorded among age groups $45-54$ and 55-64 years. Married population were seen to be $54.5 \%$ of those infected followed by those that are single among the study population at $40.9 \%$. Among the occupational groups, those engaged in business as occupation have highest rate of prevalence at $50 \%$ followed by students with $31.8 \%$ while low prevalence was seen among the civil servants.

Table 2: Socio-Demographic Characteristics of the Patients and HBV Positivity in Murtala Muhammad Specialist Hospital, Kano

\begin{tabular}{|c|c|c|}
\hline Characteristics & $\begin{array}{c}\text { Number of Samples } \\
\mathrm{N}=200,(\%)\end{array}$ & $\begin{array}{c}\text { HBsAg Positive } \\
\mathrm{N}=\mathbf{2 2},(\%)\end{array}$ \\
\hline \multicolumn{3}{|l|}{ Age group } \\
\hline $\begin{array}{l}15-24 \\
25-34 \\
35-44 \\
45-54 \\
55-64\end{array}$ & $\begin{array}{c}68(34.0) \\
74(37.0) \\
37(18.5) \\
12(6.0) \\
09(4.5)\end{array}$ & $\begin{array}{c}6(27.3) \\
10(45.4) \\
6(27.3) \\
0(0) \\
0(0)\end{array}$ \\
\hline \multicolumn{3}{|l|}{ Sex } \\
\hline Male & $90(45)$ & $16(72.7)$ \\
\hline Female & $110(55)$ & $6(27.3)$ \\
\hline \multicolumn{3}{|l|}{ Marital status } \\
\hline Single & $86(43.0)$ & $9(40.9)$ \\
\hline Married & $105(52.5)$ & $12(54.5)$ \\
\hline Widow & $8(4.0)$ & $1(4.5)$ \\
\hline Divorced & $1(0.5)$ & $0(0)$ \\
\hline \multicolumn{3}{|l|}{ Occupation } \\
\hline Business & $75(37.5)$ & $11(50.0)$ \\
\hline Students & $72(36.0)$ & $7(31.8)$ \\
\hline Civil Servants & $53(26.5)$ & $4(18.2)$ \\
\hline
\end{tabular}


For assessment of some risk factors associated with hepatitis B viral infection as shown in Table 3, only $7.5 \%$ of the recruited subjects have had hepatitis B vaccination at full dose and none is positive among them, others have never had even a single dose of the vaccine. On considering blood transfusion as a risk factor, $8.5 \%$ of the patients have history of blood transfusion and only $18.2 \%$ of them are infected. $10.5 \%$ of the patients have history of more than one sexual partner and among them $68.2 \%$ are $\mathrm{HBsAg}$ positive while lower prevalence $31.8 \%$ was observed among those without the history of multiple sexual partners. This strongly suggested that sexual promiscuity exposes one to the dangers of contracting the disease. When tribal and scarification marks were considered as risk factors, only $10 \%$ of the study population have history of scarification or tribal marks and represent only $4.5 \%$ of the infected population.

Table 3: Some Selected Risk Factors Associated with Hepatitis B Virus Infection Obtained from Murtala Muhammad Specialist Hospital, Kano

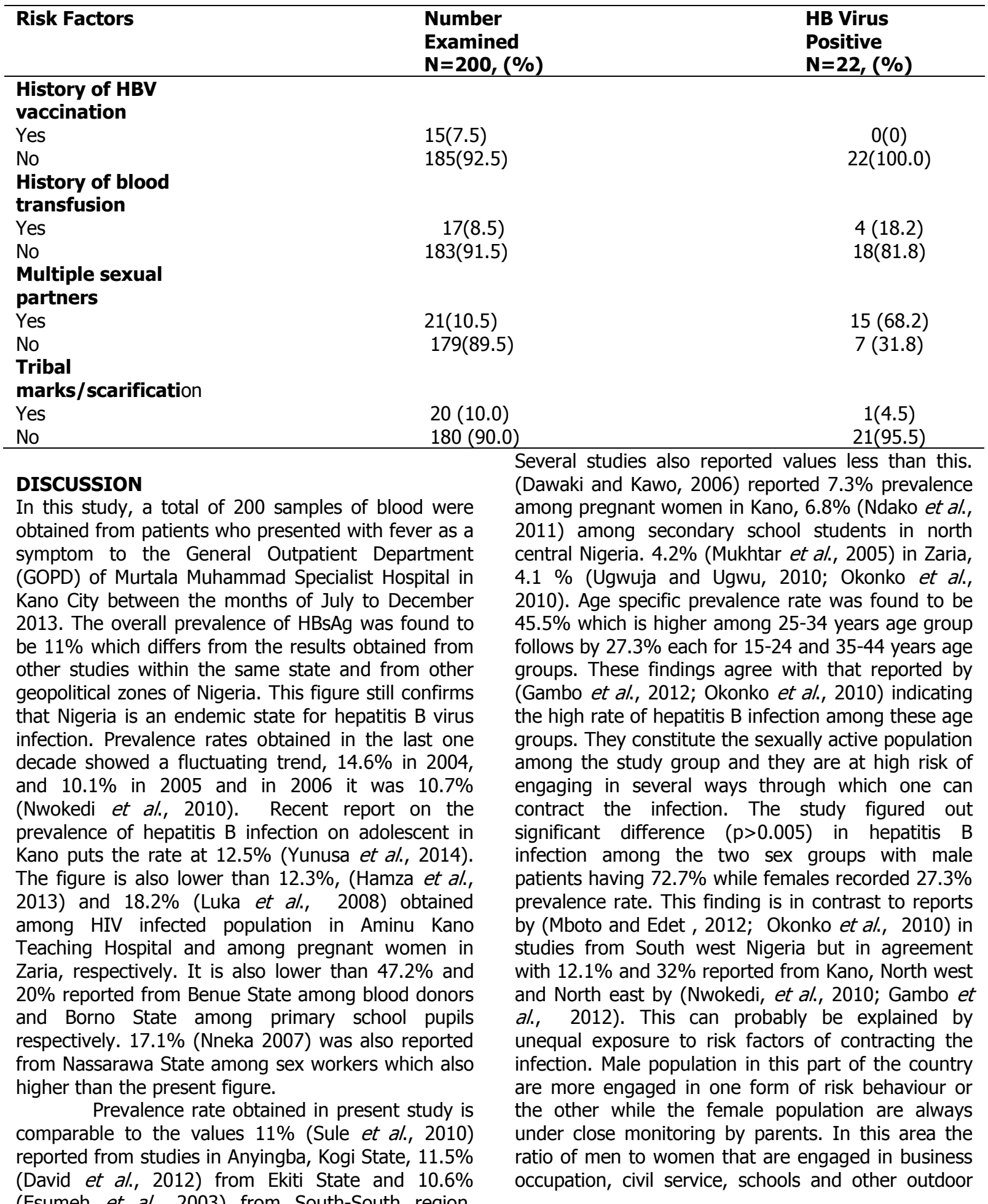


activities is significant going by their tradition, culture This study also presents prevalence of hepatitis B infection that varies according to socioeconomic status of the patients (Okonko et al., 2010; Alikor and Erhabor, 2007). Population of the study group engaged in one form of business trading or the other have high prevalence of the infection which is $50 \%$ and $31.8 \%$ among students while civil servants had the least prevalence of the infection. This is in agreement with the earlier studies that occupation is associated with the infection (Baye and Yahannes, 2007; Okonko et al., 2010). Along with this, studies in Ethiopia revealed that mechanics and drivers had $28 \%$ prevalence rate, students $20 \%$ and civil servants had $15 \%$ prevalence rates of hepatitis B infection (Baye and Yahannes, 2007).

In Nigeria $4.1 \%$ was reported among students by (Okonko et al., 2010) and 12.5\% among female adolescents students (Yunusa et al., 2014). The low prevalence rates among the civil servants may be related to high level of awareness on the preventive measures against the infection while high prevalence among those engaged in several business activities may be due low level of awareness and can engaged in various ways that could lead them to contract the infection especially sexual route as suggested by this study and by Dawaki and Kawo (2006) within same geographical areas. This study also revealed high prevalence rate among married population $54.5 \%$ while $10.9 \%$ was seen among the unmarried class because of horizontal transmission. This finding is in contrast to what was obtained in Ethiopia where $21.6 \%$ was obtained among married population while those that are singles recorded $75.7 \%$ (Baye and Yahannes 2007). It is also in contrast with the studies done in Abeokuta, south west Nigeria, where

\section{REFERENCES}

Abiodun, P.O. and Omoike, I.V. (1990). Hepatitis B surface Antigenaemia in children in BeninCity Nigeria. Nigerian journal of paediatrics. 17:27-31

Alao, O., Okwori, E., Egwu, C. and Audu, F. (2009). Seroprevalence of Hepatitis B surface antigen among Prospective blood donors in an urban Area of Benue State. The internet journal of hematology 5(2)

Alikor, E.A. and Erhabor, O.N. (2007): Seroprevalence of Hepatitis B surface antiginemia in children in tertiary health institution in Niger Delta of Nigeria. Nigerian journal of Medicine 16(3): 250-251

Baye, G. and Yahannes, M. (2007). The prevalence of HBV, HCV and Malarial parasites among Blood donors in Amhara and Tigray Regional States: Ethiopian journal of Health Development 22(1):3-7

Center for disease control and prevention (CDC). (2008). Hepatitis B virus (HBV) infection during pregnancy. Recommendations of the Advisory Committee on Immunization Practices (ACIP). Morbidity and mortality weekly report. 57 (No. RR-3): 20-21. and religion.

students recorded higher prevalence rate of $5.5 \%$ and married population recorded none (Okonkwo et al., 2010).

This study reported sexual transmission as the major route of contracting the infection with $71.5 \%$ prevalence rate among those that have history of more than one sexual partner. $17.6 \%$ of those with positive history of blood transfusion as a result of poor screening and occult HBV infection in the past had the disease. This is consistent with the findings from other studies that unprotected sexual intercourse or sexual promiscuity and unscreened blood transfusion are major route of transmitting the infection (Dawaki and Kawo, 2006; Okonkwo et al., 2010; Mboto and Edet, 2012). Some other studies recorded high prevalence of hepatitis $B$ infection among those with history of scarification or tribal marks. In this study $4.5 \%$ prevalence rate was recorded among those with history of scarification or tribal marks which is in contrast to $8.0 \%$ recorded by (Okonkwo et al., 2010). Hepatitis B virus vaccination proved to be protective in this study as none of the $7.5 \%$ of the study population with history of vaccination is hepatitis $B$ positive. This emphasizes continuous encouragement by individual, groups, Non-governmental organizations and governments to be more dedicated and committed at ensuring proper awareness and availability of the vaccine to the community. This finding is in agreement with assertion that the HBV vaccine is effective and protective (Lee et al., 2006). Although an effective vaccine is now available for HBV, not everyone will have an access to the vaccine; therefore the public health education is still the best means of combating this disease.

Cheesbrough, M. (2005). District Laboratory Practice for Tropical Countries, Part 2. Cambridge University Press, UK. 434pp.

David, O.M., Oluduro, A.O., Ariyo, A.B., Ayeni, D.I. and Famurewa, O.I. (2012). Seroepidemiological survey of hepatitis B surface antigenemia in children and adolescents in Ekiti State, Nigeria. Journal of public health and Epidemiology 5(1): 11-14

Dawaki, S.S. and Kawo, A.H. (2006). Seroprevalence of $\mathrm{HBsAg}$ in pregnant women attending urban maternity hospital in Kano: Nigerian journal of microbiology, 20:705-709

Esumeh, F.I., Ugbomoiko, D. and Isibor, J.O. (2003). Seroprevalence of HIV and Hepatitis B surface antigen (HBsAg) among blood donors in central hospital Benin City, Nigeria. Journal of medical laboratory science $12(2)$ : $52-55$

Fakunle, Y.M., Abdurahman, M.B. and Whittle, H.C. (1981). Hepatitis B virus infection in children and adults in Northern Nigeria: a preliminary survey. Transaction of the royal society of tropical medicine and hygiene. 75: 626-629.

22 Gambo, I.M., Rabiu, A.M., Muhammad, M.B. and Shugaba, A.I. (2012). Seroprevalence of 
HBsAg among Fulani Nomads in Toro North Eastern Nigeria. Global advanced Hamza, M., Samaila, A.A., Yakasai, A.M., Babashani, M., Borodo, M.M. and Habib, A.G. (2013). Prevalence of Hepatitis $B$ and $C$ virus infections among HIV-infected patients in a tertiary hospital in North western Nigeria. Nigeria journal of basic clinical sciences, 10: 76-81

Lee, C., Gong, Y., Brok, J., Boxal, E.H. and Gluud, C. (2006). Effect of Hepatitis B Immunization in Newborn infants of mothers positive for hepatitis B surface antigen: systematic review and meta analysis. British Medical Journa/332(7537):328-336k

Luka, S.A., Ibrahim, M.B. and Iliya, S. (2008). Seroprevalence of Hepatitis B surface antigen among pregnant women attending antenatal clinic in Ahmadu Bello University Teaching Hospital Zaria. Nigerian journal of parasitology. 29:38-41

Mazie, J.B., Barcus, T.T., Nicholas, J.W., Kantilaras, J., Schwartz, I.K., Andrew, C. and Baird, J.K. (2002). Hepatitis B infection and severe plasmodium falciparum malaria in Vietnamese adults: American journal of tropical medicine and hygiene, 66(2), 140142

Mboto, C.I. and Edet, E.J. (2012). Prevalence and Risk factors of Hepatis B Virus Infection among Students in University of Uyo. International journal of modern biology and medicine 2(2): 101-111

Mukhtar, H.M., Sulaiman, A.M. and Jones, M. (2005). Safety of blood transfusion: Prevalence of HBsAg In donor in Zaria: Nigerian journal of Surgical research: 7(4): 290-292

Ndako, J.A., Nwankiti, O.O., Echeonwu, G.N., Junaid, S.A., Anaele, O. and Anthony, T.J. (2011). Studies on prevalence and risk factors for hepatitis B surface antigen among secondary school Students in North central Nigeria. Serria leone journal of Biomedical research, 3(3): 163-68

Nneka, O. (2007). Seroprevalence of Hepatitis B virus infection among commercial sex workers in Keffi, Nigeria. B.Sc Dissertation (Unpublished). Nassarawa State University. 1-18

Nwokedi, E.O., Odimayo, M.S., Emokpae, A.M., Yahaya, I.A, Sadiq, M.N. and Okwori, E.E. (2010). Seroprevalence of HBsAg among patients attending Aminu Kano Teaching Hospital, Kano. Nigerian journal of medicine 19(4):423-6 research journal of Medicine and Medical Sciences 1(8): 214-217

Okonkwo, F.A., Soleye, F.A., Alli, J.A., Ojezele, M.O., Udeze, A.O., Nwanze, J.C., Adewale, O.G. and Iheanyi, O. (2010). Seroprevalence of HBsAg Antigenemia among patients in Abeokuta, south Western Nigeria. Global journal of medical research 10(2): 140149

Paulyn, T.A., Terdzungwe, T.S. and Simon, H.T. (2011). Prevalence of plasmodia and hepatitis B virus coinfection in blood donors at Bishop Murray Medical Centre, Markurdi, Benue State Nigeria: Asian pacific journal of tropical medicine: 22226

Samuel, S.O., Aderibigbe, S.A., Salami, T.A., and Babatunde, O.A. (2009). Health workers' knowledge, attitude and behaviour towards hepatitis B infection in Southern Nigeria. Int J Med Sci 1:418-24.

Sharma, S.K., Saini, N. and Chawla, Y. (2005). Hepatitis B virus: inactive carriers. Virology journal 2:82

Sule, W.F., Okonko, I.O., Ebute, A.J., Donbraye, E., Fadeyi, A., Udeze, A.O. and Alli, J.A. (2010). Farming and non farming individuals attending Grimard Catholic Hospital Anyingba Kogi State Nigeria, were Comparable in Hepatitis B surface antigen Seroprevalence. Current reaserch journal of Biological sciences 2(4): 278-282

Ugwuja, E. and Ugwu, N. (2010). Seroprevalence of Hepatitis B surface antigen and liver function test among adolescents in Abakaliki, South eastern Nigeria. The internet journal of tropical medicine $6(2$

Yunusa, I., Minjibir, A.I., Ahmad, I.M., Madobi, A.L., Abdulkadir, R.S., Huzaifa, U., Kabir, N. and Ezeanyika, L.U. (2014). Low body Mass index does not correlate with Hepatitis B surface antigen infection in Female adolescents: British journal of Applied Science and technology 4(8):1230-1237

World Health Organization. (2013). Hepatitis B Virus fact sheet no. 204. Geneva: Retrieved from: http://www.who.int/mediacentre/factsheet s/fs204/en/index.html on 08/07/2014. 